\title{
Mental health and substance use in urban left-behind children in China: a growing problem
}

Feng Wang ${ }^{\mathrm{a}}$, Leesa Lin ${ }^{\mathrm{b}}$, Jingjing Lu ${ }^{\mathrm{a}}$, Jingjing Cai ${ }^{\mathrm{a}}$, Jiayao Xu ${ }^{\mathrm{a}}, \mathrm{Xudong}_{\mathrm{Zhou}}^{\mathrm{a}}$,* a The Institute of Social and Family Medicine, Department of Public Health, School of Medicine, Zhejiang University, Hangzhou, Zhejiang Province, PR China b Faculty of Public Health Policy, London School of Hygiene \& Tropical Medicine, Kings Cross, London, UK

\begin{abstract}
Children left behind by their migrant parents in urban and rural areas represent two vulnerable but distinct populations that have emerged due to the large-scale population migrations that occur within China. In 2015, there were an estimated 28 million urban left-behind children and around 41 million rural left-behind children. The purpose of this study was to examine the mental health status and substance use behaviors of urban left-behind children and urban children still living with their parents in comparison to rural left-behind children. This study also sought to investigate how parent-adolescent communication and children's resilience may moderate or exacerbate mental health status and/or substance use across children experiencing different forms of parental migration and hukou status (household registration system), using cross-sectional data from a school-based questionnaire survey with a sample of 4565 children living in both urban and rural counties of Anhui province. Regression model results suggest that, compared to urban children who lived with both parents, urban children who were currently left-behind appeared to exhibit higher mental health difficulties (emotional symptoms and total difficulties) and more substance use (smoking and drinking). Urban left-behind children were also found to experience more mental health problems and substance use than rural left-behind children. Our results indicated that both parentadolescent communication and resilience were strongly associated with children's
\end{abstract}


mental health and substance use outcomes. These findings have significance for the creation and tailoring of interventions directed at urban left-behind children.

Keywords: left-behind children; parent-adolescent communication; resilience; mental health; substance use

\section{Introduction ${ }^{1}$}

Two demographic trends that have emerged in China in recent years deserve greater attention. The first is that, in 2011, the proportion of China's population living in urban areas $(51.3 \%)$ exceeded those living in rural areas $(48.7 \%)$ for the first time (National Bureau of Statistics of China, 2012). China has experienced rapid urbanization since the government's adoption of the reform and opening-up policy; China's urban population increased from $21.1 \%$ of the population in 1982 to $56.1 \%$ in 2015 , while the proportion of children living in urban areas increased from $16.6 \%$ in 1982 to $49.1 \%$ in 2015 (National Bureau of Statistics of China, 2016).

The second trend is a structural change in the nature of China's internal migration patterns. Large-scale population migrations have occurred in China for at least the last four decades, with the migrant population increasing from 6.6 million in 1982 to 245 million in 2017 (National Health Commission of China, 2019). In 2015, rural-to-urban migration in China was in decline, while urban-to-urban migration was increasing. There are an estimated 61 million urban-to-urban migrants in China, accounting for roughly $25 \%$ of the total migrant population (National Health Commission of China, 2019). Chinese internal migration has always been controlled by the government,

\footnotetext{
${ }^{1}$ Abbreviations

LBC: left-behind children; U-CLBC: current LBC with urban hukou status; U-PLBC: previous LBC with urban hukou status; U-NLBC: never LBC with urban hukou status; R-CLBC: current LBC with rural hukou status;

R-PLBC: previous LBC with rural hukou status.

PACS: Parent and Adolescent Communication Scale; CD-RISC: Connor-Davidson Resilience Scale;

SDQ: Strength and Difficulties Questionnaires.
} 
mainly through the household registration system, otherwise known as the hukou system. This is a place-based public resource distribution and management system which prevents migrants (rural-to-urban migrants or urban-to-urban migrants) and their children from accessing local social benefits in the cities to which they migrate, including medical insurance and public education (Zhou and Cheung, 2017). The increase in urban-to-urban migration has also resulted in a large and ever-growing population of urban left-behind children (LBC). From 2005 to 2015, estimates for the number of urban LBC increased from 14.7 to 28.3 million, while the number of rural LBC declined by 18 million, to around 40.5 million, across China (UNICEF, 2018). LBC are children "who live in their original domicile, but have not lived with their parents for over six months, as either one or both parents have migrated" (UNICEF, 2018). Urban LBC refer to LBC whose household registration locations are in urban areas. Rural LBC refer to LBC whose household registration locations are in rural areas.

Historically, in most circumstances, LBC only referred to children left-behind in rural areas. In the past two decades, a number of researchers have sought to determine the effects of parental migration on rural LBC. A systematic review and meta-analysis study demonstrated that parental migration is detrimental to the health of rural LBC, with no evidence of any benefit (Fellmeth et al., 2018). Compared with rural children living with both parents, rural LBC faced increased risks of depression, suicidal ideation, substance use and conduct disorders (Fellmeth et al., 2018; Lu, 2012; Wen et al., 2015; Wu et al., 2015). Despite the plethora of studies on rural LBC, far too little attention has been paid to urban LBC. This lack of research constrains our ability to examine the effects of parental migration on urban child development.

There is well-established evidence from the fields of child psychology and family studies that effective regular communication with parents can protect the mental health 
of children and reduce their risk of substance use. Munz defines parent-adolescent communication as "the verbal and non-verbal interaction between parents and children within a family system" (Munz, 2015). Parent-adolescent communication is an indicator of the strength of the parent-adolescent relationship and is emphasized as an important family factor that contributes to children's development (Ackard et al., 2006). Studies have demonstrated that higher levels of parent-adolescent communication are associated with better mental health and fewer behavioral problems (Lanz et al., 1999; Liu, 2003; Wang et al., 2013; Ying et al., 2015). For example, using data from the Eating Among Teens Survey (2001 Project EAT) in the United States, Ackard et al's study on 4767 adolescents demonstrated that perceived low parental communication levels were associated with depression, substance use and low self-esteem (Ackard et al., 2006). Ponnet et al analyzed data from 2707 children in Belgium and found that poor parentadolescent communication was significantly related to children's suicidal ideation and self-harming behavior (Ponnet et al., 2005). Research on rural LBC in China has also started to examine the association between parent-adolescent communication and children's mental health and substance use. Some recent studies suggest that the quality of rural LBC's parent-adolescent communication is significantly lower than that of their non-left-behind counterparts (Su et al., 2013). Wang et al's study in Anhui province found that rural LBC experienced greater problems in communicating with their parents than did children living with both parents, and that experiencing problems in communicating with parents was associated with higher levels of mental health difficulties (Wang et al., 2019). Despite a growing body of research on the association between parent-adolescent communication and rural LBC's mental health and substance use, there is a lack of literature addressing this association for children leftbehind in urban areas, particularly in the context of urban-to-urban migration in China. 
Resilience has been defined as "a process in which individuals use their abilities, strengths, capacities, and resources to maintain healthy functioning or positively adapt within the context of risk experiences or adversities" (Luthar et al., 2000; Masten and Obradovic, 2006). Existing literature provides convincing evidence on the association between resilience and adolescents' mental health and substance use (Ann et al., 1990; Jordan and Graham, 2012; Martinez et al., 2009; Suniya and Edward, 1991). Nrugham et al found an association between children's resilience and lifetime violent events and attempted suicide, using data from 2464 students followed over 6 years in Norway (Nrugham et al., 2010). Drawing upon a sample of 2311 children who experienced the devastating Sichuan earthquake in China, Gan et al found that resilience moderated the effects of negative events on adolescent depressive symptoms (Gan et al., 2013). Studies in the Chinese context have also demonstrated the protective effects of resilience on the mental health and substance use of LBC in rural areas (Ai and $\mathrm{Hu}$, 2016; Guo et al., 2015; Luo et al., 2016; Shi et al., 2016). Despite the well-established evidence for the association between resilience and child mental health and behavior, no previous study has tried to examine this association in urban LBC.

There is no empirical evidence on mental health and substance use for urban LBC in China, in part because this population is a relatively new phenomenon. To better understand the mental health and substance use of children in the rural-urban and urbanurban migration contexts, this study aims to compare urban $\mathrm{LBC}$ and rural $\mathrm{LBC}$ in Anhui Province, and to investigate how parent-adolescent communication and resilience affects children with regard to different forms of parental migration and hukou status. Anhui is an underdeveloped province with a population of 63 million (National Bureau of Statistics of China, 2019). It ranked 22 ${ }^{\text {nd }}$ in GDP (Gross Domestic Product) per capital in Mainland China in 2018 (National Bureau of Statistics of China, 
2019) and is a feeder province for migrant workers, with both rural-to-urban migrants and urban-to-urban migrants, and housing nearly 5.1 million LBC (Duan et al., 2013). Since the majority of migration flows are within the country, it is not uncommon that migrant parents return home after living apart from their child for an extended period. The effects on children after the return of parents is worthy of discussion based on our previous studies (Zhao et al., 2017; Wang et al., 2019). Then we compared five groups of children in this study: LBC with urban hukou status, previous LBC with urban hukou status, children with urban hukou status living with their parents, LBC with rural hukou status, and previous LBC with rural hukou status.

\section{Materials and Methods}

\subsection{Participants and procedure}

A cross-sectional survey using self-reported questionnaires was conducted in schools in urban and rural locations in Anhui Province. The urban location chosen for this study was Wuhu, the second largest city in the province. To make our sample more comparable, four townships (from Wuwei and Nanling county) at low economic development levels in Wuhu were further chosen to serve as the rural locations for this study. The survey was carried out from April 2018 to March 2019.

Currently, around 55\% of the total population of Anhui is classified as urban, so we aimed for an urban and rural sample split that reflected this dynamic. Eighteen schools, ten in urban Wuhu, and eight in the two rural counties of Wuwei and Nanling, were randomly selected from the list of registered schools provided to us by the Education Commission. One school declined to participate when initially approached, so the next school on the list was selected. In each school, all students from Grades 58 were eligible for the study. Grades 1-4 were excluded to ensure the necessary literacy 
level for completion of the questionnaire.

Before the survey, informed consent was obtained from both the head teachers and the student participants. Parents were informed two days in advance of the survey administration by letter, which was distributed to children in class to take home. The questionnaires were completed by children in the classroom without teachers present, and were administered under exam conditions. A group of research assistants was trained and present in the classrooms to help students understand questions, when necessary. All the students matching the inclusion criteria were invited to participate in this survey and completed the questionnaire anonymously. Students were assured of the confidentiality of their questionnaire information.

\subsection{Measures}

\subsubsection{Socio-demographic variables}

The questionnaire started with a socio-demographic section to collect children's demographic characteristics, including age, gender, grade, household wealth level, parental highest education level and number of siblings. As children are unlikely to be aware of household income, household wealth level was measured by asking a question about perceived wealth: How do you feel about your family's economic situation in comparison with others in the community: much better off, better off, the same, poorer and much poorer. Parental education level referred to the higher education level of their two parents and was characterized as "primary school or lower," "middle school," "high school or above," and "do not know."

\subsubsection{Left-behind status and household registration status}

Left-behind status and household registration status were identified and 
differentiated by asking the respondents the following questions: "Did your father (and/or mother) migrate to another place for work and does he (and/or she) no longer live with you for a period of more than six months? (The answer options were "yes, currently migrates," “yes, previously migrated," and "no, never"); "What's your registered permanent residence? (The answer options were "urban registered permanent residence" and "rural registered permanent residence"). These questions differentiated the participants into five categories: 1) U-CLBC: current LBC with urban hukou status; 2) U-PLBC: previous LBC with urban hukou status; 3) U-NLBC: never LBC with urban hukou status; 4) R-CLBC: current LBC with rural hukou status; 5) R-PLBC: previous LBC with rural hukou status. In data analysis, the left-behind status and household registration status were recorded as four dummy variables, with the first category, current LBC with urban hukou status, being the reference group.

\subsubsection{The Parent and Adolescent Communication Scale (PACS)}

The Chinese version of the Parent-Adolescent Communication Scale (PACS) was used to assess parent-adolescent communication (Barnes and Olson, 1985; Lanz et al., 1999; Shek, 2000). This 20-item self-reported instrument is composed of two sub-scales: one that measures the extent of problems in family communication (the Problems in Family Communication Scale), and one that assesses the degree of openness in family communication (the Open Family Communication Scale). Each sub-scale has 10 items. The greater value of the raw scores of the Open Family Communication Scale indicates a good and open parent-adolescent communication. Sample items are: "I find it easy to discuss problems with my father/mother" and "My father/mother is always a good listener." However, the greater value of the raw scores of the Problems in Family Communication Scale means a higher degree of problems. Sample items including "I 
don't think I can tell my father/mother how I really feel about some things" and "I'm careful about what I say to my father/mother" (Barnes and Olson, 1985). These two sub-scales were taken together to calculate the total scale score, with a higher score signifying better parent-adolescent communication. Each participant was asked to complete both the Father Form and Mother Form of the PACS. The PACS demonstrates high internal consistency and construct validity in the Chinese context (Xia et al., 2004; Ying et al., 2015). The Cronbach's Alpha coefficient (internal consistency) for the Openness sub-scale, Problems sub-scale and the total scale with the current sample were $0.90,0.79$ and 0.84 for mothers, and $0.93,0.83$ and 0.87 for fathers, respectively.

\subsubsection{The Connor-Davidson Resilience Scale (CD-RISC)}

Resilience was measured with the Chinese version of the Connor-Davidson Resilience Scale (CD-RISC) (Connor and Davidson, 2003; Yu et al., 2011). The CDRISC consists of 25 items, using 5-point Likert-type responses from "not true at all" (0) to "true nearly all of the time" (4) (Connor and Davidson, 2003). This scale is rated based on how the participant has felt over the past month. The total score ranges from 0 to 100 , with higher scores corresponding to higher levels of resilience. The Chinese version of the CD-RISC was proven to have construct validity and internal consistency (Yu et al., 2011). In the current study, the Cronbach's Alpha coefficient was 0.92.

\subsubsection{The Strength and Difficulties Questionnaires (SDQ)}

The Strength and Difficulties Questionnaires (SDQ) is one of the most widely used screening instruments, developed by Goodman to measure child and adolescent mental health across the world (Goodman, 1997, 1999). It has a proven record of reliability and validity scores in the Chinese context (Du et al., 2008; Yao et al., 2009). The SDQ 
comprises 25 items, which are indexed on four difficulty sub-scales (emotional symptoms, conduct problems, hyperactivity/inattention, and peer problem), and a prosocial behavior sub-scale. All sub-scale scores but the pro-social behavior sub-scale can be aggregated into a total difficulties score. A high score represents greater difficulties, except for the pro-social behavior sub-scale, where a lower score indicates higher difficulties. The respondents were asked to rate themselves over the past six months. The Cronbach's Alpha coefficient for each sub-scale is as follows: 0.74 for emotional symptoms; 0.78 for conduct problems; 0.72 for hyperactivity; 0.67 for peer problem, and 0.76 for pro-social behavior.

\subsubsection{Substance use behavior}

Specific questions on substance use behavior were assessed by three items adapted from the Youth Risk Behavior Survey (Kann et al., 1995). Three kinds of substance use behavior were assessed: 1) Have you ever tried cigarette smoking, even one or two puffs? 2) Have you ever had at least one drink of alcohol other than a few sips? 3) Have you ever been drunk after you had alcohol? The response options were "Yes" and "No." These items were used partly based on pilot feedback and our previous work (Wang et al., 2017).

\subsection{Statistical analysis}

One-way analyses of variance (for continuous variables) or chi-square tests (for categorical variables) were applied to compare demographic characteristic among the five groups of children. As non-parametric data, Kruskal-Wallis H tests (for continuous variables) or chi-square tests (for categorical variables) were performed to compare group differences in terms of PACS, CD-RISC, SDQand substance use behavior. 
Following this, post hoc comparisons were conducted among these groups. Multiple linear regression models were conducted to assess the associations between SDQ outcomes and parental migration status. Binary logistic regression models were performed to explore the effects of parental migration on children's substance use behaviors (ever smoked, ever drank alcohol, and ever been drunk). Both the multiple linear regression models and the binary logistic regression models are adjusted for socio-demographics (gender, grade, household wealth level, parental education level and number of siblings), PACS and CD-RISC. The interactions between covariates and migration status were also tested. Data management and analysis were carried out using Statistical Package for Social Science (SPSS 24.0; IBM Corp., NY, USA) for windows. A two-tailed $p$ value of $<0.05$ was regarded as statistically significant.

\section{Results}

A total of $53935^{\text {th }}-8^{\text {th }}$ grade students from 18 schools in Anhui were selected for the study sample. Among these, 5253 respondents signed the consent form and completed the questionnaire, resulting in a response rate of $97 \%$. Given that other forms of parental absence could exert a different effect on children, children whose parents have divorced or passed away were not included $(n=688)$. Therefore, the final sample for analysis included 4565 students, comprising 1093 U-CLBC, 857 U-PLBC , 890 UNLBC, 1251 R-CLBC and 474 R-PLBC. Additional analyses were conducted to test whether the 688 other parental absence cases and the remaining 4565 participants were significantly different in their socio-demographic characteristic, and the results showed no significant differences.

As can be seen in Table 1, the mean age of the total sample was 13.0 (SD 1.3) with U-NLBC being slightly younger (mean 12.8, SD 1.3) than the other four groups. 
Overall, there were fewer female (43.4\%) than male (56.6\%) participants, and this did not differ across the five groups. Nearly $30 \%$ of U-NLBC came from wealthier households, compared with $25 \%$ from the four left-behind groups. However, there were no significant differences among all studied groups regarding self-rated perceived household wealth levels. Parents of urban children had higher education levels when compared to rural groups, while U-NLBC's parents demonstrated the highest level of education. U-NLBC's parents (35.2\%) were more likely than R-CLBC's (14.9\%) and R-PLBC's (18.6\%) parents to have an education level of high school or above. In our sample, about one-tenth of the students did not know their parents' education level. Approximately two-thirds of respondents in the overall sample were the only child in their family, but the percentages of being an only child were higher for the U-CLBC (73.7\%), U-PLBC (70.9\%) and R-PLBC (66.4\%) groups, and lower for the U-NLBC $(64.2 \%)$ and R-CLBC (65.5\%) groups.

Table 2 presents the observed differences in mean total and sub-scale scores from PACS and CD-RISC among the five groups of students. There were significant differences between different groups of students with respect to mother-adolescent openness sub-scale score $(\mathrm{H}=141.23, \mathrm{p}<0.001)$, mother-adolescent problem sub-scale score $(H=146.45, p<0.001)$, mother-adolescent total score $(H=164.88, p<0.001)$, fatheradolescent openness sub-scale score $(\mathrm{H}=186.51, \mathrm{p}<0.001)$, father-adolescent problem sub-scale score $(H=268.96, p<0.001)$, father-adolescent total score $(H=255.08, p<0.001)$ and resilience score $(H=55.21, \mathrm{p}<0.001)$. Compared to the other groups, the R-CLBC and R-PLBC had the lowest scores on the openness sub-scales and total scales of mother- and father-adolescent communication, and had the highest scores on the problem sub-scales of mother- and father-adolescent communication. We observed significant differences between U-PLBC and U-NLBC on the openness sub-scale score 
and total scale score of mother-adolescent communication. Among urban children, UPLBC reported the lowest openness sub-scale score and total scale score and had the highest problem sub-scale score for father-adolescent communication. Regarding the CD-RISC, R-CLBC and R-PLBC reported the lowest scores on the resilience dimension. There were also significant differences between U-PLBC and U-NLBC in resilience scores.

Table 3 shows the mean SDQ scores for all sub-scales and total difficulties across the five groups of children. U-NLBC had lower mean scores for total difficulties, as well as lower mean sub-scale scores for emotional symptoms and hyperactivity, as compared to other groups of children. According to post-hoc tests, there were no significant differences between the U-CLBC, U-PLBC, R-CLBC and R-PLBC in total or in difficulties sub-scale scores. In terms of pro-social behavior, R-CLBC had the lowest scores compared to the other groups.

Table 3 also illustrates the frequencies of individual substance use behaviors across different groups of participants. There were significant between-group differences in all three kinds of substance use behaviors. The frequencies of ever smoking $(10.5 \%)$ and drinking (29.8\%) were lowest in the U-NLBC group. In general, R-CLBC $(30.5 \%)$ were more likely to have ever been drunk than were the other groups.

Table 4 shows the regression results of SDQ sub-scales and total difficulties scores that illustrated significant between-groups differences in Table 3. After adjusting for all covariates, U-NLBC, R-CLBC and R-PLBC were more likely to have lower emotional symptoms scores and lower total difficulties scores than U-CLBC. R-CLBC and RPLBC tended to be less disadvantaged in terms of hyperactivity, as compared to UCLBC. No significant differences were found among U-CLBC, U-PLBC and U-NLBC in hyperactivity score. Older children seemed to have less emotional symptoms $(\beta=-$ 
$0.10, \mathrm{p}<0.001)$ and total difficulties $(\beta=-0.22, \mathrm{p}<0.001)$, but were more hyperactive $(\beta=0.06, p<0.05)$, when compared to younger children. Although girls were much more likely to have emotional difficulties $(\beta=0.59, \mathrm{p}<0.001)$, they scored higher on pro-social behavior $(\beta=0.57, \mathrm{p}<0.001)$. Household wealth level was negatively associated with emotional symptoms and total difficulties. Children who experienced higher levels of openness in mother-adolescent communication were less likely to have hyperactivity problems $(\beta=-0.02, \mathrm{p}<0.01)$ and total difficulties $(\beta=-0.05, \mathrm{p}<0.01)$, and more likely to have pro-social behavior $(\beta=0.05, \mathrm{p}<0.001)$. Experiencing problems communicating with their mother or father was positively associated with emotional symptoms, hyperactivity and total difficulties. Children who showed higher resilience scores tended to have lower emotional symptoms scores $(\beta=-0.02, p<0.001)$, lower hyperactivity scores $(\beta=-0.05, p<0.001)$ and lower total difficulties scores $(\beta=-0.09$, $\mathrm{p}<0.001)$, and tended to have higher pro-social scores $(\beta=0.06, \mathrm{p}<0.001)$.

The logistic regression analysis results for behavior problems by LBC status, PACS, CD-RISC and demographic characteristics are summarized in Table 5. U-NLBC were less likely to exhibit smoking $(\mathrm{OR}=0.63, \mathrm{p}<0.01)$ and drinking behaviors $(\mathrm{OR}=0.76, \mathrm{p}<0.05)$, whereas $\mathrm{R}-\mathrm{CLBC}(\mathrm{OR}=1.49, \mathrm{p}<0.05)$ tended to be more likely to have experienced drunkenness after consuming alcohol when compared to U-CLBC. Age and gender showed significant associations with different substance use behavior in both positive and negative directions. Older children were more susceptible to ever having smoked $(\mathrm{OR}=1.18, \mathrm{p}<0.001)$ and ever having drunk alcohol $(\mathrm{OR}=1.16, \mathrm{p}<0.001)$ when compared to younger children. Female children were less likely to ever having smoked $(\mathrm{OR}=0.57, \mathrm{p}<0.001)$ and ever being drunk after consuming alcohol $(\mathrm{OR}=0.71$, $\mathrm{p}<0.01)$. Mother-adolescent openness in communication, rather than father-adolescent openness in communication, was negatively associated with children ever having 
smoked $(\mathrm{OR}=0.97, \mathrm{p}<0.01)$ and ever having drunk alcohol $(\mathrm{OR}=0.98, \mathrm{p}<0.01)$. Children who experienced higher levels of problems in mother-adolescent communication were more likely to have ever smoked $(\mathrm{OR}=1.07, \mathrm{p}<0.001)$ and ever drunk alcohol $(\mathrm{OR}=1.05, \mathrm{p}<0.001)$. In addition, children who have better resilience reported being less likely to ever have smoked.

\section{Discussion}

By drawing upon data selected from one Chinese province with widely varying levels of socioeconomic development, our findings highlight an important emerging problem in China. While the health impact of parental migration on rural LBC has been well documented, whether and to what extent migrating is beneficial or detrimental to the development and well-being of urban LBC has not been previously explored. This study represents an initial attempt to examine how left-behind experiences contribute to the mental health and substance use behaviors of children living in the context of urban China. In particular, we investigated the associations of parent-adolescent communication and resilience with the mental health and substance use behaviors of children.

Firstly, the data we obtained from cities in Anhui represents a snapshot of city demography in developing urban areas of China. These cities are examples of the less developed urban areas of China in which there are a growing number of urban-to-urban migrants. The most important finding of this study is that the current experience of prolonged separation from migrant parents had similar negative effects on the mental health and substance use behaviors of urban children as is seen in rural children, after controlling for other variables. As the study demonstrated, compared to native urban children living with their parents, urban children currently left-behind by their 
migrating parents demonstrated greater susceptibility to mental health difficulties, and exhibited significantly more behavior problems. Children affected by parental migration face a series of challenges to their development; LBC, including both those left behind in their rural hometowns and those left behind in urban locations, face difficulties in receiving emotional support and supervision from their parents, which can be detrimental to their mental health and contribute to behavioral problems (Fellmeth et al., 2018; UNICEF, 2018). This is evident in Fellmeth et al's meta-analysis study, which included a total of 264967 children $(\mathrm{LBC}=106167$; non-LBC $=158800)$ and suggested that LBC had a 52\% increased risk of depression, an $85 \%$ increased risk of anxiety, a $24 \%$ increased risk of substance use, and a $70 \%$ increased risk of suicidal ideation than did non-LBC (Fellmeth et al., 2018). However, further investigations are needed to elaborate the risks faced specifically by urban LBC.

Secondly, the existing literature generally regards rural children as the most vulnerable group, but the results of this study demonstrated worse mental health outcomes among U-CLBC than among R-CLBC and R-PLBC when adjustments were made for confounders. U-CLBC, R-CLBC and R-PLBC have consistently similar scores in the SDQ sub-scale scores and total difficulties scores. However, after adjustment, U-CLBC scored higher for emotional symptoms, hyperactivity and total difficulties than did R-CLBC and R-PLBC, which suggested that LBC in urban areas may be the most vulnerable group. There are several possible explanations for this result. This finding is consistent with the UNICEF's report -- 'The state of the world's children 2012: children in an urban world' -- which disrupted the commonly-held notion that children who live in cities are necessarily better off than those in rural communities. In fact, disparities and poverty within cities cause many children to lack access to health care and sanitation, despite living alongside these services (UNICEF, 2012). As in many 
other societies, education is the key vehicle for social mobility and prosperity in China. Educational achievement is usually a top concern for children and their entire family; this is particularly true for urban children whose parents are generally better educated, and these expectations may increase children's psychological stress (Bian, 2002). However, more studies are needed to explore the differences between urban LBC and rural $\mathrm{LBC}$.

Thirdly, parent-adolescent communication, encapsulating mother- and fatheradolescent communication, was found to be an important protective factor for children's mental health and substance use. As this study demonstrated, open motheradolescent communication was particularly beneficial for lessening children's hyperactivity and total difficulties, and helpful for developing pro-social behavior. In contrast, experiencing problems in communicating with their mother and father was strongly related to children's emotional symptoms, hyperactivity and total difficulties. These findings further support the previous evidence that children with a higher frequency of and more effective communication with their migrant parents tended to exhibit a good parent-adolescent relationship, better school performance and psychological development, whereas those with low frequency of or ineffective parentadolescent communication showed greater psychological difficulties (Givaudan and Pick, 2013; Lu, 2012; Wang et al., 2019; Zhao et al., 2015). As prior studies have suggested, good and regular communication with parents is important in maintaining secure attachment between children and their absent parents (Wang et al., 2015). However, due to long distances between them, absent parents may not be able to contact their children in a timely and proper manner, thus leading to the development of insecure attachment relationships in children. Children who have insecure attachment relationships with their parents may exhibit more internalizing problems (e.g., 
emotional symptoms) and externalizing problems (e.g., hyperactivity) when they cope with stress in life. The strong negative influence exhibited by problematic motheradolescent communication on children's substance use behavior that we identified in this study is worthy of further discussion. As our results suggest, poor parent-adolescent communication is associated with ever having smoked and ever having drunk alcohol. It is well understood that mothers play a crucial role in fostering children, and most children prefer to communicate with their mothers than with their fathers (Collinson, 2010). In addition to the disrupted parent-adolescent relationship due to migration, children having problems in communicating with their mother may cause further damage to family dynamics and may result in extra adverse effects on children's behavioral problems (Collinson, 2010). However, further research is necessary to more fully explore why mother-adolescent communication has a greater effect on children's substance use than does father-adolescent communication in China.

Low resilience in children is unsurprisingly associated with mental health difficulties and substance use. As our study demonstrates, children with higher resilience are significantly less likely to be prone to the three mental difficulties we studied (emotional symptoms, hyperactivity and total difficulties) and substance use (ever smoking). This aligns with the compensatory model of resilience that emphasizes the role of protective factors in promoting psychological functioning and mitigating the negative influence of adversities (Collinson, 2010; Norman et al., 1984). A systematic literature review, which included 35 studies, documented the effects of resilience-based intervention programmes on mental health promotion and the mitigation of behavioral problems among children and adolescents living in low and middle income countries (Barry et al., 2013). Tam et al's pilot trial also showed that the resilience-based intervention programme is feasible and potentially efficacious in decreasing depression 
symptoms among rural-to-urban migrant children in China (Tam et al., 2019). Therefore, targeted resilience-based interventions should be prioritized in the migrant-sending communities.

This study has several limitations. Firstly, the study sample, originating from one province in China, lacks national representativeness despite the rigorous sampling procedure and large sample size. Access to nationally representative data, which we are currently pursuing, will help provide a more complete understanding of the mental health and behavioral problems of children in the massive population migration context. Secondly, any interpretations of the results of the SDQ need to be considered with caution, especially when considering what the statistical differences between the scores actually imply. While there were significant differences between groups across the crude scores of the SDQ, the range across all of the scores was narrow, raising questions regarding its clinical significance. A total difficulties score of $>14$ is only "slightly raised" in the English version of SDQ (Anna and Robert, 2009). However, the highest mean total difficulty score in this study was 12.7 (SD 5.4) for R-CLBC with 12.4 (SD 5.7) for U-CLBC; therefore the majority of participants fall within normal limits. These differences are small, and it is important to treat the interpretation of statistically significant differences with caution. Thirdly, the cross-sectional nature of our research prohibits us from drawing causal conclusions from the observed associations among parental migration, parent-adolescent communication, resilience, child mental health and substance use. For instance, there exists the possibility that children with better mental health are more likely to have good communication practices with their parents, rather than vice versa. Future research using a longitudinal design should be conducted to explore these relationships. Fourth, our measures of the key variables were all selfreported, due to the fact that this survey was only administered to students in a school 
setting. Future studies may wish to collect data from multiple informants (e.g., parents or caregivers) to provide triangulation and achieve a more sophisticated data set.

\section{Conclusions}

Despite these limitations, the findings of this study enhance our understanding of LBC's mental health and substance use in urban China and provide important implications for the development of interventions and prevention programs for promoting these children's well-being. Firstly, the present study strongly suggests that urban LBC have markedly higher mental health difficulties than U-NLBC, independent of socio-demographic variables, parent-adolescent communication and resilience. These findings also add to the body of work indicating that U-CLBC show greater susceptibility to mental health problems than R-CLBC and R-PLBC. Given these findings, the structural change in population migration that has led to an increase in urban LBC should be of higher concern. The Chinese government has expressed concern about the well-being and development of $\mathrm{LBC}$, and a number of policy announcements on this topic have been made in the last decade. However, these policies almost exclusively target rural LBC. With the knowledge that urban LBC are the most vulnerable LBC group to mental health difficulties, the government should design policy frameworks that offer support to urban children. Secondly, given the different associations we observed between mother-adolescent communication and fatheradolescent communication on children's mental health and substance use, special attention must be paid to improve the quality of children's communication with their mothers. For example, local governments and migrant-sending communities can provide communication training program for mothers so that they can better understand the importance of parent-adolescent communication and have adequate communication 
skills to compensate for the negative consequences of parental absence. Lastly, the findings of this study expand on previous research by demonstrating that resilience could serve as a protective factor for children, with benefits in reducing negative mental health outcomes and substance use behavior. As mentioned above, resilience-based intervention programs have proven their effectiveness for promoting psycho-social factors and mitigating mental health symptoms among migrant children in China (Tam et al., 2019). Future studies should assess the feasibility and efficacy of such programs among LBC in urban China.

\section{References:}

Ackard, D. M., Neumark-Sztainer, D., Story, M., Perry, C., 2006. Parent-child connectedness and behavioral and emotional health among adolescents. Am. J. Prev. Med 30(1), 59-66.

Ai, H., Hu, J., 2016. Psychological resilience moderates the impact of social support on loneliness of "left-behind" children. J. Health Psychol 21(6), 1066-1073.

Ann S, M., Karin M, B., Norman, G., 1990. Resilience and development: contributions from the study of children who overcome adversity. Dev. Psychopathol 4(2), 425-444.

Anna Goodman, Goodman, R., 2009. The Strengths and Difficulties Questionnaire (SDQ) as a dimensional measure of child mental health. J. Am. Acad. Child Adolesc. Psychiatr 48(4), 400-403.

Barnes, H. L., Olson, D. H., 1985. Parent-adolescent communication and the circumplex model. Child Dev 56(2), 438-447.

Barry, M. M., Clarke, A. M., Jenkins, R., Patel, V., 2013. A systematic review of the effectiveness of mental health promotion interventions for young people in low and middle income countries. BMC Public Health 13, 835.

Bian, Y., 2002. Chinese social stratification and social mobility. Annu. Rev. Sociol 28(1), 91-116.

Collinson, M. A., 2010. Striving against adversity: the dynamics of migration, health and poverty in rural South Africa. Glob. Health Action 3(1), 50-64 .

Connor, K. M., Davidson, J. R. T., 2003. Development of a new resilience scale: The Connor-Davidson Resilience Scale (CD-RISC). Depress. Anxiety 18(2), 76-82.

Du Y., Kou, J., Coghill, D., 2008. The validity, reliability and normative scores of the parent, teacher and self-report versions of the Strengths and Difficulties Questionnaire in China. Child Adolesc Psychiatry Ment Health 2(1), 8.

Duan, C., Lv, L., Guo, J., Wang, Z., 2013. Survival and development of left-behind children in rural China: based on the analysis of sixth census data. Population Journal 35(3), 37-49.

Fellmeth, G., Rose-Clarke, K., Zhao, C., Busert, L. K., Zheng, Y., Massazza, A., et al., 2018. Health impacts of parental migration on left-behind children and adolescents: a systematic review and meta-analysis. The Lancet 392(10164), 2567-2582.

Gan, Y., Xie, X., Wang, T., Rodriguez, M. A., Tang, C. S., 2013. Thriving in the shadow of the 2008 Sichuan earthquake: two studies on resilience in adolescents. J. Health Psychol 18(9), 1232-1241.

Givaudan, M., Pick, S., 2013. Children left behind: how to mitigate the effects and facilitate emotional and psychosocial development. Child Abuse Negl 37(12), 1080-1090.

Goodman, R., 1997. The strengths and difficulties questionnaire: a research note. J. Child Psychol. Psychiatry 38(5), 581-586.

Goodman, R.,1999. The extended version of the strengths and difficulties questionnaire as a guide to child psychiatric caseness and consequent burden. J. Child Psychol. Psychiatry 40(5), 791-799.

Guo, X., Liu, Q., Wang, H., Huang, K., Lei, X., Zhang, F., et al., 2015. Resilience and its influential factors in leftbehind middle school students in yunyang county of rural three gorges areas in China: a cross-sectional survey. Public Health 129(11), 1479-1487.

Jordan, L. P., Graham, E., 2012. Resilience and well-being among children of migrant parents in south-east Asia. Child Dev 83(5), 1672-1688.

Kann, L., Warren, C. W., Harris, W. A., Collins, J. L., Douglas, K. A., Collins, M. E., et al., 1995. Youth risk behavior surveillance--United States, 1993. J. Sch. Health 65(5), 163-171.

Lanz, M., Iafrate, R., Rosnati, R., Scabini, E., 1999. Parent-child communication and adolescent self-esteem in separated, intercountry adoptive and intact non-adoptive families. J. Adolesc 22(6), 785-794.

Liu, Y. L., 2003. Parent-child interaction and children's depression: the relationships between parent-child interaction 
and children's depressive symptoms in Taiwan. J. Adolesc 26(4), 447-457.

Lu, Y., 2012. Household migration, social support, and psychosocial health: the perspective from migrant-sending areas. Soc. Sci. Med 74(2), 135-142.

Luo, Y., Wang, H., Lei, X., Guo, X., Huang, K., Liu, Q., 2016. Resilience in rural left-behind middle school students in yunyang county of the three gorges area in China: a prospective cohort study. BMC Psychiatry 16, 77.

Luthar, S. S., Cicchetti, D., Becker, B., 2000. The construct of resilience: a critical evaluation and guidelines for future work. Child Dev 71(3), 543-562.

Munz, E.A., 2015. Parent-child communication. The International Encyclopedia of Interpersonal Communication, $1-5$.

Martinez-Torteya, C., Anne, B. G., von Eye, A., Levendosky, A. A., 2009. Resilience among children exposed to domestic violence: the role of risk and protective factors. Child Dev 80(2), 562-577.

Masten, A. S., Obradovic, J., 2006. Competence and resilience in development. Ann. NY Acad. Sci 1094(1), 13-27. National Bureau of Statistics of China, 2012. Statistical communiqué on the 2011 national economic and social development.

http://www.stats.gov.cn/english/NewsEvents/201202/t20120222_26575.html/ (accessed 24 February 2020).

National Bureau of Statistics of China, 2016. Statistical Communiqué of the People's Republic of China on the 2015 National Economic and Social Development.

http://www.stats.gov.cn/english/PressRelease/201602/t20160229 1324019.html/ (accessed 24 February 2020).

National Health Commission of China, 2019. China migration population development report 2018. http://www.chinaldrk.org.cn/wjw/\#/achievement/publication/ded7ec35-00d4-40c6-8f73-1094df971447/ (accessed 24 February 2020).

National Bureau of Statistics of China, 2019. Statistical communiqué of the People's Republic of China on the 2018 national economic and social development.

http://www.stats.gov.cn/english/PressRelease/201902/t20190228 1651335.html/ (accessed 24 February 2020).

Norman Garmezy, Ann S. Masten, Tellegen, A., 1984. The study of stress and competence in children: a building block for developmental psychopathology. Child Dev 55(1), 97-111.

Nrugham, L., Holen, A., Sund, A. M., 2010. Associations between attempted suicide, violent life events, depressive symptoms, and resilience in adolescents and young adults. J. Nerv. Ment. Dis 198(2), 131-136.

Ponnet, K., Vermeiren, R., Jespers, I., Mussche, B., Ruchkin, V., Schwab-Stone, M., et al., 2005. Suicidal behaviour in adolescents: associations with parental marital status and perceived parent-adolescent relationship. J. Affect. Disord 89(1-3), 107-113.

Shek, D. T., 2000. Differences between fathers and mothers in the treatment of, and relationship with, their teenage children: perceptions of Chinese adolescents. Adolescence 35(137), 135-146.

Shi, J., Chen, Z., Yin, F., Zhao, J., Zhao, X., Yao, Y., 2016. Resilience as moderator of the relationship between leftbehind experience and mental health of Chinese adolescents. Int. J. Soc. Psychiatr 62(4), 386-393.

Su, S., Li, X., Lin, D., Xu, X., Zhu, M., 2013. Psychological adjustment among left-behind children in rural China: the role of parental migration and parent-child communication. Child Care Health Dev 39(2), 162-170.

Suniya S, L., Edward, Z., 1991. Vulnerability and competence: a review of research on resilience in childhood. Am. J. Orthopsychiatr 61(1), 6-22.

Tam, C. C., Li, X., Benotsch, E. G., Lin, D., 2019. A resilience-based intervention programme to enhance psychological well-being and protective factors for rural-to-urban migrant children in China. Appl. Psychol.-Health and Well Being.

UNICEF, 2012. The state of the world's children 2012: children in an urban world.

https://www.unicef.org/sowc2012/ (accessed 24 February 2020).

UNICEF, 2018. Population status of children in China in 2015: facts and figures.

https://www.unicef.cn/atlas-2018-cn/ (accessed 24 February 2020).

Wang, B., Stanton, B., Li, X., Cottrell, L., Deveaux, L., Kaljee, L., 2013. The influence of parental monitoring and parent-adolescent communication on Bahamian adolescent risk involvement: a three-year longitudinal examination. Soc. Sci. Med 97, 161-169.

Wang, F., Lin, L., Xu, M., Li, L., Lu, J., Zhou, X., 2019. Mental health among left-behind children in rural China in relation to parent-child communication. Int. J. Environ. Res. Public Health 16(10), 1855

Wang, F., Zhou, X., Hesketh, T., 2017. Psychological adjustment and behaviours in children of migrant workers in China. Child Care Health Dev 43(6), 884-890.

Wang, L., Feng, Z., Yang, G., Yang, Y., Dai, Q., Hu, C., et al., 2015. The epidemiological characteristics of depressive symptoms in the left-behind children and adolescents of Chongqing in China. J. Affect. Disord 177, 36-41.

Wen, M., Su, S., Li, X., Lin, D., 2015. Positive youth development in rural China: the role of parental migration. Soc. Sci. Med 132, 261-269.

Wu, Q., Lu, D., Kang, M., 2015. Social capital and the mental health of children in rural China with different experiences of parental migration. Soc Sci Med 132, 270-277.

Xia, Y. R., Xie, X., Zhou, Z., Defrain, J., Defrain, J., Combs, R., 2004. Chinese adolescents' decision-making, parentadolescent communication and relationships. Marriage Fam. Rev 36(1-2), 119-145.

Yao, S., Zhang, C., Zhu, X., Jing, X., McWhinnie, C. M., Abela, J. R., 2009. Measuring adolescent psychopathology: psychometric properties of the self-report strengths and difficulties questionnaire in a sample of Chinese adolescents. J. Adolesc. Health 45(1), 55-62.

Ying, L., Ma, F., Huang, H., Guo, X., Chen, C., Xu, F., 2015. Parental monitoring, parent-adolescent communication, and adolescents' trust in their parents in China. PLoS One, 10(8), e134730.

Yu, X., Lau, J. T. F., Mak, W. W. S., Zhang, J., Lui, W. W. S., Zhang, J., 2011. Factor structure and psychometric 
properties of the Connor-Davidson Resilience Scale among Chinese adolescents. Compr. Psychiat 52(2), 218-224. Zhou, s., Cheung, M., 2017. Hukou system effects on migrant children's education in China: learning from past disparities. Int. J. Soc. Work 60, 1327-1342.

Zhao, C., Wang, F., Li, L., Zhou, X., Hesketh, T., 2017. Long-term impacts of parental migration on Chinese children's psychosocial well-being: mitigating and exacerbating factors. Soc. Psychiatry Psychiatr. Epidemiol 52(6), 669-677.

Zhao, J., Liu, X., Wang, M., 2015. Parent-child cohesion, friend companionship and left-behind children's emotional adaptation in rural China. Child Abuse Negl 48, 190-199. 


\section{Result}

Table 1 Sample characteristics by parental migration status and household registration status, Mean (SD)/N(\%)

\begin{tabular}{|c|c|c|c|c|c|c|c|}
\hline & $\begin{array}{c}\text { U-CLBC, } \\
\mathrm{N}=1093\end{array}$ & $\begin{array}{c}\text { U-PLBC, } \\
\mathrm{N}=857\end{array}$ & $\begin{array}{c}\text { U-NLBC, } \\
\mathrm{N}=890\end{array}$ & $\begin{array}{c}\text { R-CLBC, } \\
\mathrm{N}=1251\end{array}$ & $\begin{array}{c}\text { R-PLBC, } \\
\mathrm{N}=474\end{array}$ & F or $\chi 2$ & $P$ value \\
\hline Age & $13.1(1.3)$ & $13.1(1.3)$ & $12.8(1.3)$ & $13.1(1.2)$ & $13.2(1.2)$ & 15.67 & $<0.001$ \\
\hline Gender & & & & & & 8.10 & 0.088 \\
\hline Male & $648(60.3)$ & $487(57.4)$ & $491(56.1)$ & $678(54.9)$ & $257(55.0)$ & & \\
\hline Female & $427(39.7)$ & $361(42.6)$ & $384(43.9)$ & $558(45.1)$ & $210(45.0)$ & & \\
\hline Grade & & & & & & 24.89 & $<0.001$ \\
\hline Grade 5 Grade 6 & $456(41.8)$ & $334(39.1)$ & $441(49.6)$ & $538(43.0)$ & $184(38.9)$ & & \\
\hline Grade 7 Grade 8 & $636(58.2)$ & $521(60.9)$ & $449(50.4)$ & $712(57.0)$ & $289(61.1)$ & & \\
\hline Household wealth level & & & & & & 13.10 & 0.108 \\
\hline Much better off/better off & $277(25.6)$ & $195(23.0)$ & $254(29.1)$ & $317(25.5)$ & $120(25.7)$ & & \\
\hline The same & $716(66.2)$ & $586(69.3)$ & $566(64.9)$ & $818(65.9)$ & $306(65.5)$ & & \\
\hline Poorer/much poorer & $88(8.1)$ & $65(7.7)$ & $52(6.0)$ & $106(8.5)$ & $41(8.8)$ & & \\
\hline Parental education level & & & & & & 199.03 & $<0.001$ \\
\hline Primary school or lower & $116(10.6)$ & $78(9.1)$ & $72(8.1)$ & $204(16.3)$ & $101(21.4)$ & & \\
\hline Middle school & $580(53.1)$ & $450(52.5)$ & $394(44.3)$ & $739(59.1)$ & $246(52.0)$ & & \\
\hline High school or above & $293(26.8)$ & $238(27.8)$ & $313(35.2)$ & $187(14.9)$ & $88(18.6)$ & & \\
\hline Do not know & $104(9.5)$ & $91(10.6)$ & $111(12.5)$ & $121(9.7)$ & $38(8.0)$ & & \\
\hline Any sibling & & & & & & 29.50 & $<0.001$ \\
\hline Yes & $287(26.3)$ & $249(29.1)$ & $318(35.8)$ & $431(34.5)$ & $159(33.6)$ & & \\
\hline No & $805(73.7)$ & $607(70.9)$ & $571(64.2)$ & $820(65.5)$ & $314(66.4)$ & & \\
\hline
\end{tabular}


Table 2 Communication and resilience outcomes by parental migration status and household registration status, Mean(SD)

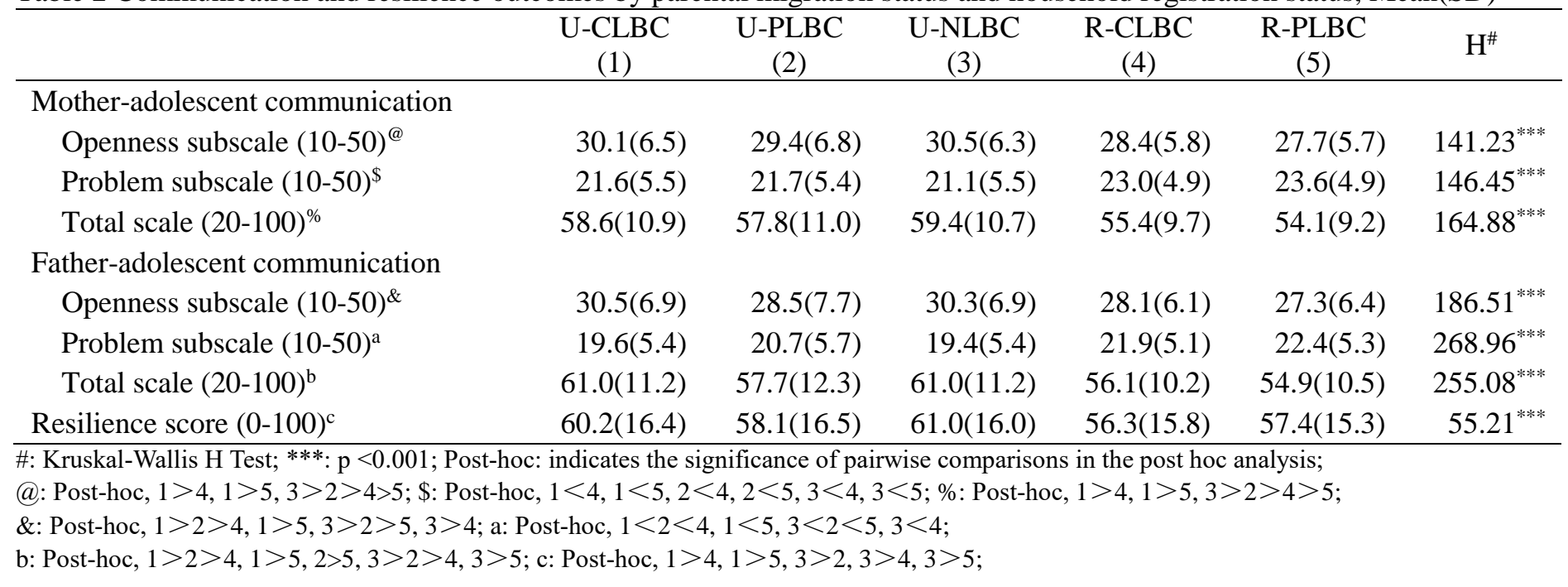

Table 3 Mental health and behaviors outcomes by parental migration status and household registration status, Mean (SD)/N(\%) 


\begin{tabular}{|c|c|c|c|c|c|c|}
\hline & $\begin{array}{l}\text { U-CLBC } \\
\text { (1) }\end{array}$ & $\begin{array}{l}\text { U-PLBC } \\
\text { (2) }\end{array}$ & $\begin{array}{l}\text { U-NLBC } \\
\text { (3) }\end{array}$ & $\begin{array}{l}\text { R-CLBC } \\
\text { (4) }\end{array}$ & $\begin{array}{l}\text { R-PLBC } \\
\text { (5) }\end{array}$ & $\mathrm{H}^{\#}$ or $\chi 2$ \\
\hline Emotional symptoms $(0-10)^{\mathrm{a}}$ & $3.4(2.3)$ & $3.5(2.4)$ & $3.1(2.2)$ & $3.6(2.2)$ & $3.4(2.1)$ & $30.61^{* * *}$ \\
\hline Conduct problems $(0-10)$ & $2.5(1.7)$ & $2.5(1.7)$ & $2.4(1.6)$ & $2.5(1.6)$ & $2.5(1.6)$ & 7.68 \\
\hline Hyperactivity $(0-10)^{\mathrm{b}}$ & $3.8(2.2)$ & $4.0(2.2)$ & $3.7(2.2)$ & $4.1(2.1)$ & $4.0(2.1)$ & $26.25^{* * *}$ \\
\hline Peer problems $(0-10)$ & $2.6(1.7)$ & $2.6(1.7)$ & $2.5(1.7)$ & $2.7(1.7)$ & $2.6(1.6)$ & 8.99 \\
\hline Total difficulties score $(0-40)^{c}$ & $12.4(5.7)$ & $12.6(5.8)$ & $11.6(5.6)$ & $12.7(5.4)$ & $12.5(5.2)$ & $30.51^{* * * *}$ \\
\hline Pro-social $(0-10)^{\mathrm{d}}$ & $7.2(2.1)$ & $7.0(2.1)$ & $7.2(2.1)$ & $6.9(2.0)$ & $7.0(2.0)$ & $21.76^{* * *}$ \\
\hline Ever smoking ${ }^{\mathrm{e}}$ & & & & & & $36.73^{* * *}$ \\
\hline Yes & 192(17.6) & $165(19.3)$ & $93(10.5)$ & $234(18.7)$ & $97(20.5)$ & \\
\hline No & $900(82.4)$ & $692(80.7)$ & $796(89.5)$ & $1017(81.3)$ & $376(79.5)$ & \\
\hline Ever drinking $^{\mathrm{f}}$ & & & & & & $24.93^{* * *}$ \\
\hline Yes & $407(37.2)$ & $319(37.2)$ & $265(29.8)$ & $495(39.6)$ & $188(39.7)$ & \\
\hline No & $686(62.8)$ & $538(62.8)$ & $625(70.2)$ & $756(60.4)$ & $285(60.3)$ & \\
\hline Ever been drunk ${ }^{g}$ & & & & & & $17.58^{* * *}$ \\
\hline Yes & 93(22.9) & $67(21.1)$ & $52(19.7)$ & $151(30.5)$ & $55(29.6)$ & \\
\hline No & $313(77.1)$ & 251(78.9) & $212(80.3)$ & $344(69.5)$ & 131(70.4) & \\
\hline
\end{tabular}

\#: Kruskal-Wallis H Test; ***: $\mathrm{p}<0.001$; Post-hoc: indicates the significance of pairwise comparisons in the post hoc analysis;

a: Post-hoc, $1>3,2>3,4>3,5>3$; b: Post-hoc, $2>3,4>3,5>3$; c: Post-hoc, $1>3,2>3,4>3,5>3$; d: Post-hoc, 1>4, $3>4$;

e: Post-hoc, $1>3,2>3,4>3,5>3$; f: Post-hoc, $1>3,2>3$, 4>3, 5>3; g: Post-hoc, $4>2,4>3$; 
status and household registration status, $\beta(95 \%$ confidence interval $)$

\begin{tabular}{|c|c|c|c|c|}
\hline & $\begin{array}{c}\text { Emotional } \\
\text { symptoms }^{@}\end{array}$ & Hyperactivity ${ }^{\#}$ & Pro-social $^{\$}$ & $\begin{array}{c}\text { Total difficulties } \\
\text { score }^{\&}\end{array}$ \\
\hline \multicolumn{5}{|c|}{ Parental migration status (ref: U-CLBC) } \\
\hline U-PLBC & $-0.03(-0.22,0.17)$ & $0.03(-0.15,0.21)$ & $-0.01(-0.16,0.15)$ & $-0.23(-0.68,0.22)$ \\
\hline U-NLBC & $-0.23(-0.43,-0.04)^{*}$ & $-0.04(-0.22,0.14)$ & $-0.08(-0.24,0.07)$ & $-0.53(-0.98,-0.09)^{*}$ \\
\hline R-CLBC & $-0.20(-0.37,-0.02)^{*}$ & $-0.18(-0.35,-0.02)^{*}$ & $0.04(-0.10,0.19)$ & $-0.79(-1.20,-0.38)^{* * *}$ \\
\hline R-PLBC & $-0.48(-0.72,-0.25)^{* * *}$ & $-0.29(-0.51,-0.08)^{* *}$ & $0.07(-0.13,0.26)$ & $-1.37(-1.92,-0.83)^{* * *}$ \\
\hline Age & $-0.10(-0.16,-0.05)^{* * *}$ & $0.06(0.01,0.11)^{*}$ & $0.02(-0.03,0.06)$ & $-0.22(-0.33,-0.10)^{* * *}$ \\
\hline \multicolumn{5}{|l|}{ Gender (ref: male) } \\
\hline Female & $0.59(0.46,0.72)^{* * *}$ & $0.07(-0.05,0.18)$ & $0.57(0.47,0.68)^{* * *}$ & $0.18(-0.12,0.48)$ \\
\hline \multicolumn{5}{|c|}{ Household wealth level (ref: much better off/better off) } \\
\hline The same & $-0.12(-0.27,0.03)$ & $-0.13(-0.27,0.01)$ & $-0.08(-0.21,0.04)$ & $-0.57(-0.92,-0.22)^{* *}$ \\
\hline Poorer/much poorer & $0.44(0.17,0.70)^{* *}$ & $0.07(-0.17,0.31)$ & $0.04(-0.18,0.25)$ & $0.89(0.29,1.49)^{* *}$ \\
\hline \multicolumn{5}{|c|}{ Parental education level (ref: primary school or lower) } \\
\hline Middle school & $0(-0.20,0.20)$ & $0.03(-0.15,0.21)$ & $-0.16(-0.32,0)$ & $-0.13(-0.59,0.32)$ \\
\hline High school or above & $0.07(-0.16,0.30)$ & $-0.04(-0.25,0.17)$ & $-0.02(-0.21,0.17)$ & $-0.06(-0.58,0.46)$ \\
\hline Do not know & $-0.13(-0.40,0.14)$ & $-0.03(-0.28,0.21)$ & $-0.46(-0.68,-0.24)^{* * *}$ & $-0.17(-0.79,0.45)$ \\
\hline \multicolumn{5}{|l|}{ Any sibling (ref: yes) } \\
\hline No & $0.10(-0.04,0.24)$ & $-0.01(-0.13,0.12)$ & $0.11(0,0.23)^{*}$ & $0.04(-0.28,0.36)$ \\
\hline \multicolumn{5}{|c|}{ Mother-adolescent communication } \\
\hline Openness subscale & $0(-0.01,0.02)$ & $-0.02(-0.03,-0.01)^{* *}$ & $0.05(0.04,0.06)^{* * *}$ & $-0.05(-0.08,-0.02)^{* *}$ \\
\hline Problem subscale & $0.11(0.09,0.13)^{* * *}$ & $0.09(0.07,0.11)^{* * *}$ & $0.01(0,0.03)$ & $0.28(0.24,0.32)^{* * *}$ \\
\hline \multicolumn{5}{|c|}{ Father-adolescent communication } \\
\hline Openness subscale & $-0.01(-0.02,0)$ & $0(-0.01,0.01)$ & $0.01(0.01,0.03)^{*}$ & $-0.01(-0.04,0.03)$ \\
\hline Problem subscale & $0.05(0.03,0.07)^{* * *}$ & $0.04(0.02,0.05)^{* * *}$ & $-0.01(-0.03,0)$ & $0.17(0.13,0.21)^{* * * *}$ \\
\hline Resilience score & $-0.02(-0.02,-0.01)^{* * *}$ & $-0.05(-0.05,-0.04)^{* * *}$ & $0.06(0.06,0.07)^{* * *}$ & $-0.09(-0.10,-0.08)^{* * *}$ \\
\hline
\end{tabular}

@: $\mathrm{N}=3997$, adjusted $\mathrm{R}^{2}=0.191 ; \quad \#: \mathrm{N}=3994$, adjusted $\mathrm{R}^{2}=0.286 ; \quad \$: \mathrm{N}=3993$, adjusted $\mathrm{R}^{2}=0.357 ; \quad \& \cdot \mathrm{N}=3935$, adjusted $\mathrm{R}^{2}=0.318 ;$

$*: \mathrm{p}<0.05 ; * *: \mathrm{p}<0.01 ; * * *: \mathrm{p}<0.001$

Table 5 Regression coefficients for behavior problems on parental migration status and household registration status, OR( $95 \%$ confidence interval) 


\begin{tabular}{|c|c|c|c|}
\hline & Ever smoking $^{\#}$ & Ever drinking $\$$ & Ever been drunk ${ }^{\&}$ \\
\hline \multicolumn{4}{|c|}{ Parental migration status (ref: U-CLBC) } \\
\hline U-PLBC & $1.13(0.87,1.47)$ & $0.92(0.75,1.13)$ & $0.80(0.54,1.20)$ \\
\hline U-NLBC & $0.63(0.47,0.85)^{* *}$ & $0.76(0.62,0.94)^{*}$ & $0.89(0.58,1.35)$ \\
\hline R-CLBC & $1.00(0.79,1.28)$ & $0.97(0.80,1.17)$ & $1.49(1.07,2.09)^{*}$ \\
\hline R-PLBC & $0.98(0.72,1.34)$ & $0.92(0.72,1.18)$ & $1.42(0.92,2.19)$ \\
\hline Age & $1.18(1 \cdot 10,1 \cdot 27)^{* * * *}$ & $1.16(1.09,1.22)^{* * *}$ & $0.97(0.88,1.07)$ \\
\hline \multicolumn{4}{|l|}{ Gender (ref: male) } \\
\hline Female & $0.57(0.48,0.69)^{* * * *}$ & $0.98(0.86,1.13)$ & $0.71(0.55,0.92)^{* *}$ \\
\hline \multicolumn{4}{|c|}{ Household wealth level (ref: much better off/better off) } \\
\hline The same & $0.91(0.73,1.13)$ & $0.92(0.78,1.09)$ & $0.82(0.61,1.11)$ \\
\hline Poorer/much poorer & $0.95(0.67,1.35)$ & $0.85(0.64,1.12)$ & $0.86(0.53,1.41)$ \\
\hline \multicolumn{4}{|c|}{ Parental education level (ref: primary school or lower) } \\
\hline Middle school & $0.90(0.70,1.17)$ & $1.26(1.02,1.56)^{*}$ & $0.81(0.56,1.17)$ \\
\hline High school or above & $0.93(0.68,1.25)$ & $1.19(0.94,1.52)$ & $0.74(0.47,1.15)$ \\
\hline Do not know & $0.71(0.48,1.04)$ & $1.23(0.92,1.64)$ & $1.08(0.65,1.80)$ \\
\hline \multicolumn{4}{|l|}{ Any sibling (ref: yes) } \\
\hline No & $1.15(0.94,1.39)$ & $0.99(0.85,1.15)$ & $1.27(0.97,1.67)$ \\
\hline \multicolumn{4}{|c|}{ Mother-adolescent communication } \\
\hline Openness subscale & $0.97(0.96,0.99)^{* *}$ & $0.98(0.96,0.99)^{* *}$ & $1.00(0.98,1.03)$ \\
\hline Problem subscale & $1.07(1.04,1.09)^{* * * *}$ & $1.05(1.03,1.07)^{* * * *}$ & $1.03(0.99,1.06)$ \\
\hline \multicolumn{4}{|c|}{ Father-adolescent communication } \\
\hline Openness subscale & $0.99(0.98,1.01)$ & $0.99(0.97,1.00)$ & $0.98(0.96,1.01)$ \\
\hline Problem subscale & $1.02(1.00,1$. & $1.01(0.99,1.02)$ & $0.99(0.96,1.02)$ \\
\hline Resilience score & $0.99(0.98,0.99)^{* *}$ & $1.00(0.99,1.00)$ & $1.00(0.99,1.00)$ \\
\hline
\end{tabular}



